\title{
Deep hypothermic circulatory arrest and antegrade selective cerebral perfusion during ascending aorta-hemiarch replacement: A retrospective comparative study
}

Marco Di Eusanio, MD

Ronald M. J. Wesselink, MD, PhD ${ }^{\mathrm{b}}$

Wim J. Morshuis, MD, PhD

Karl M. Dossche, MD, $\mathrm{PhD}^{\mathrm{a}}$

Marc A. A. M. Schepens, MD, PhD
From the Departments of Cardiopulmonary Surgery $^{\mathrm{a}}$ and Anaesthesiology and Intensive Care, ${ }^{\mathrm{b}}$ St Antonius Hospital, Nieuwegein, The Netherlands.

Received for publication April 25, 2002; revisions requested June 14, 2002; revisions received July 26, 2002; accepted for publication Aug 6, 2002.

Address for reprints: Marco Di Eusanio, MD, Department of Cardiopulmonary Surgery, St Antonius Hospital, Koekoekslaan 1, 3435 CM Nieuwegein, The Netherlands (E-mail: m_dieus@hotmail.com).

J Thorac Cardiovasc Surg 2003;125:849-54

Copyright $(\odot 2003$ by The American Association for Thoracic Surgery

$0022-5223 / 2003 \$ 30.00+0$

doi: $10.1067 / \mathrm{mtc} .2003 .8$
Objective: We sought to compare the results of ascending aorta-hemiarch replacement by using 2 different methods of cerebral protection in terms of hospital mortality, neurologic outcome, and systemic morbidity and to determine predictive risk factors associated with hospital mortality and neurologic outcome after ascending aorta-hemiarch replacement.

Methods: Between January 1995 and September 2001, 289 patients (mean age, $62.2 \pm 13.2$ years; urgent status, 122/289 [42.2\%]) underwent ascending aortahemiarch replacement with the aid of antegrade selective cerebral perfusion (161 patients) or deep hypothermic circulatory arrest (128 patients).

Results: Overall hospital mortality was $11.4 \%$ (deep hypothermic circulatory arrest group, 13.3\%; antegrade selective cerebral perfusion group, $9.9 \% ; P=$ .375). A logistic regression analysis revealed acute type A dissection $(P=.001$; odds ratio, 4.3) and age of greater than 70 years $(P=.019$; odds ratio, 2.5) to be independent predictors of hospital mortality. The permanent neurologic dysfunction rate was $9.3 \%$ (deep hypothermic circulatory arrest group, $12.5 \%$; antegrade selective cerebral perfusion group, $7.6 \% ; P=.075)$. Logistic regression analysis revealed acute type A dissection $(P=.001$; odds ratio, 6.7) and history of cerebral infarction-transient ischemic attack $(P=.038$; odds ratio, $3.4)$ to be independent predictors of permanent neurologic dysfunction. The transient neurologic dysfunction rate was $8.0 \%$ (deep hypothermic circulatory arrest group, 7.1\%; antegrade selective cerebral perfusion group, $8.7 \% ; P=$ $.530)$. Acute type A dissection ( $P=.001$; odds ratio, 5.1) was indicated as an independent predictor of transient neurologic dysfunction by means of logistic regression. Renal dysfunction (postoperative creatinine level of $>250 \mu \mathrm{mol} / \mathrm{L}$; deep hypothermic circulatory arrest, 10 [7.8\%]; antegrade selective cerebral perfusion, $6[3.7 \%] ; P=.030$ ), as well as prolonged intubation time (deep hypothermic circulatory arrest, $3.8 \pm 6.3$ days; antegrade selective cerebral perfusion, $2.2 \pm 2.5$ days; $P=.005)$ were more common in the deep hypothermic circulatory arrest group.

Conclusion: The use of antegrade selective cerebral perfusion and deep hypothermic circulatory arrest during ascending aorta-hemiarch replacement resulted in acceptable hospital mortality and neurologic outcome. Reduced postoperative intubation time and better renal function preservation were observed in the antegrade selective cerebral perfusion group. 


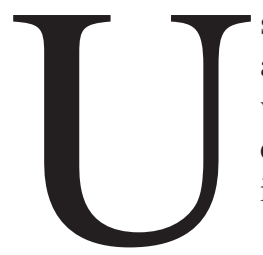

se of optimal methods of brain, spinal, and myocardial protection, as well as prevention and treatment of hemorrhage and coagulopathy, are primary concerns during operations of the thoracic aorta.

Current methods of brain protection include deep hypothermic circulatory arrest (DHCA), retrograde cerebral perfusion, and antegrade selective cerebral perfusion (ASCP). All 3 methods have advantages and disadvantages.

In our institute ASCP is currently the method of choice for cerebral protection, especially for patients requiring complex aortic arch repairs. When a circulatory arrest time of less than 30 minutes is anticipated, the selection of the brain protection method (between DHCA and ASCP) depends on the surgeon's preference.

This study was undertaken to determine the predictive risk factors associated with hospital mortality and neurologic outcome in patients undergoing ascending aortahemiarch replacement with ASCP and DHCA. A comparison between the 2 techniques was also performed in terms of hospital mortality, neurologic outcome, and systemic morbidity.

\section{Patients and Methods}

Between January 1995 and September 2001, 289 patients underwent ascending aorta-hemiarch replacement at the St Antonius Hospital, Department of Cardiothoracic Surgery, Nieuwegein, The Netherlands.

Medical records were reviewed for clinical variables, including preoperative status, intraoperative data, and early postoperative complications (see Appendix). There were 189 (65.3\%) men and $100(34.7 \%)$ women, with a mean age of $62.2 \pm 13.2$ years (age range, 23-85 years). The indications for surgical intervention were acute type A dissection in $122(42.2 \%)$ patients and chronic postdissection aneurysm or degenerative aneurysm in $167(57.8 \%)$ patients.

Cerebral protection was achieved by means of DHCA in 128 patients (DHCA group, 44.3\%) and ASCP and moderate hypothermia in 161 patients (ASCP group, 55.7\%). The year in which the operation was performed did not influence the selection of the brain preservation technique used. Patient demographics were essentially similar in the 2 groups (Table 1).

All patients having elective surgery underwent preoperative evaluation of cerebral circulation with Doppler ultrasonography of the extracranial vessels, digital subtraction angiography of the extracranial and intracranial circulation, carotid compression tests with monitoring by means of electroencephalography to evaluate occlusion intolerance, or a transcranial Doppler ultrasonographic study when available.

\section{Operative Technique}

Induction of anesthesia was obtained with $2 \mathrm{mg} / \mathrm{kg}$ propofol, 2 $\mu \mathrm{g} / \mathrm{kg}$ fentanyl, and $0.1 \mathrm{mg} / \mathrm{kg}$ pancuronium. Anesthesia was maintained with propofol and fentanyl. For all patients, $\mathrm{pH}$ balance control was carried out by using the alpha-stat method. No phar- macologic neuroprotective agents were administered. Aprotinin was used sporadically.

Cerebral monitoring was achieved by means of a right radial arterial pressure line, electroencephalography, regional oxygen saturation in the bilateral frontal lobes with near-infrared spectroscopy, and transcranial Doppler ultrasonographic measurement of the blood velocity of the middle cerebral arteries.

The proximal thoracic aorta was approached by means of a median sternotomy in all cases. After systemic heparinization, cardiopulmonary bypass (CPB) was instituted with a cannula for arterial return to the ascending aorta or the femoral artery and a venous single 2-stage cannula in the right atrium. The left side of the heart was vented through the right superior pulmonary vein. Myocardial protection was achieved with cold crystalloid cardioplegia and topical pericardial cooling, maintaining the myocardial temperature at or below $14^{\circ} \mathrm{C}$.

In the DHCA group core cooling was instituted during CPB to produce profound hypothermia. During this period, usually requiring 30 to 40 minutes, the proximal repair was performed. The head was packed in ice to prevent warming of the central nervous system. When a flat-line electroencephalogram was achieved, circulation was arrested, and the distal repair was carried out. On completion of the procedure, gradual warming was carried out by means of CPB, limiting the gradient between blood and body temperature to less than $10^{\circ} \mathrm{C}$, with a maximum blood temperature of $37^{\circ} \mathrm{C}$. A warming blanket was also used. Central warming was usually discontinued at a rectal temperature of $35^{\circ} \mathrm{C}$.

Details of our cannulation technique and method of ASCP with moderate hypothermic circulatory arrest have been previously described. ${ }^{1,2}$ Briefly, after CPB was instituted and the patients were cooled to a nasopharyngeal temperature of $22^{\circ} \mathrm{C}$ to $26^{\circ} \mathrm{C}$, the systemic circulation was arrested, and the aneurysm was opened. With the patient in the Trendelenburg position, $15 \mathrm{~F}$ retrograde coronary sinus perfusion cannulas (Medtronic DLP) connected to the oxygenator with a separate single-roller pump head were inserted into the innominate and left common carotid arteries through the aortic lumen. The left subclavian artery was clamped or occluded with a Fogarty catheter (Baxter Healthcare Corp) to avoid the steal phenomenon.

Cerebral perfusion was initiated at a rate of 10 $\mathrm{mL} \times \min ^{-1} \times \mathrm{kg}^{-1}$ and adjusted to maintain a right radial arterial pressure of between 40 and $70 \mathrm{~mm} \mathrm{Hg}$.

During open distal anastomosis, blood perfusion to the lower half of the body from the femoral artery, when cannulated, was arrested or reduced to $500 \mathrm{~mL} / \mathrm{min}$.

The extent of the aortic replacement and the associated procedures are listed in Table 2.

\section{Statistical Analysis}

Continuous variables were expressed as the mean $\pm 1 \mathrm{SD}$ and were analyzed by using the unpaired 2-tailed $t$ test. Categoric variables were presented as percentages and were analyzed with the $\chi^{2}$ test or Fisher exact test when appropriate. All preoperative and intraoperative variables were first analyzed by using univariate analysis to determine whether any single factor influenced hospital mortality and neurologic outcome. Variables that achieved a $P$ value of less than .05 in the univariate analysis were examined by using multivariate analysis with forward stepwise logistic regres- 
TABLE 1. Patient demographics

\begin{tabular}{|c|c|c|c|c|}
\hline & $\begin{array}{l}\text { Total group } \\
\text { (n = 289), n } \\
(\%)\end{array}$ & $\begin{array}{c}\text { DHCA group } \\
\text { (n= 128), n } \\
(\%)\end{array}$ & $\begin{array}{c}\text { ASCP group } \\
\text { (n = 161), n } \\
(\%)\end{array}$ & $P$ value \\
\hline Male sex & $189(65.3)$ & $81(63.3)$ & $108(67.5)$ & .454 \\
\hline Age $(y)$ & $62.2 \pm 13.2$ & 63.0 & 61.5 & .315 \\
\hline Acute type $A$ dissection & $122(42.2)$ & 58 (45.3) & $64(39.8)$ & .342 \\
\hline History of hypertension & $54(18.7)$ & $17(13.3)$ & $37(23.0)$ & .048 \\
\hline Diabetes & $7(2.4)$ & $3(2.3)$ & $4(2.4)$ & .156 \\
\hline CAD & $24(8.3)$ & $16(12.5)$ & $8(5.5)$ & .030 \\
\hline Creatinine $>120 \mu \mathrm{mol} / \mathrm{L}$ & $26(9.0)$ & $11(8.6)$ & $15(9.3)$ & .223 \\
\hline History of Cl-TIA & $18(6.2)$ & $7(5.5)$ & $11(6.8)$ & $\begin{array}{l}.634 \\
.218\end{array}$ \\
\hline $\mathrm{EF}>50 \%$ & 264 (91.3) & $114(89.1)$ & $150(93.2)$ & \\
\hline $30 \%<\mathrm{EF}<50 \%$ & $25(8.7)$ & $14(10.9)$ & $11(6.8)$ & \\
\hline Previous cardiac operation & $31(10.7)$ & $14(10.9)$ & $17(10.6)$ & .918 \\
\hline
\end{tabular}

$C A D$, Coronary artery disease; $C l$, cerebral infarction; $E F$, ejection fraction.

TABLE 2. Extent of replacement and associated procedures

\begin{tabular}{|c|c|c|c|c|}
\hline & $\begin{array}{c}\text { Total group, } \\
\text { n (\%) }\end{array}$ & $\begin{array}{c}\text { DHCA, } \\
\text { n (\%) }\end{array}$ & $\begin{array}{l}\text { ASCP, } \\
\text { n (\%) }\end{array}$ & $P$ value \\
\hline Extent of replacement & & & & .001 \\
\hline Ascending aorta & $129(44.6)$ & $87(68.0)$ & $42(26.1)$ & \\
\hline Hemiarch & $160(55.4)$ & $41(32.0)$ & $119(73.9)$ & \\
\hline Associated procedures (all combined) & $152(52.6)$ & $64(50)$ & $88(54.7)$ & .431 \\
\hline AVR & $24(8.3)$ & $19(14.8)$ & $5(3.1)$ & .001 \\
\hline Bentall procedure & $80(27.7)$ & $22(17.2)$ & $58(36.0)$ & .001 \\
\hline Aortic root remodeling & $12(9.5)$ & $2(1.6)$ & $10(6.2)$ & .043 \\
\hline Aortic resuspension & $12(4.2)$ & $3(2.3)$ & $9(5.6)$ & .169 \\
\hline Homograft & $15(5.2)$ & $11(8.6)$ & $4(2.5)$ & .030 \\
\hline CABG & $24(8.3)$ & $16(12.5)$ & $8(5.0)$ & .030 \\
\hline
\end{tabular}

$A V R$, Aortic valve replacement; $C A B G$, coronary artery bypass grafting.

sion to evaluate independent risk factors for hospital mortality, permanent neurologic dysfunction (PND), and transient neurologic dysfunction (TND).

The analysis for PND (stroke or coma) and TND (postoperative confusion, agitation, delirium, prolonged obtundation, or transient parkinsonism with negative brain computed tomographic scanning results and complete resolution before discharge) were conducted separately. Risk factors for PND were examined in all patients who survived the operation long enough to undergo neurologic evaluation. Risk factors for TND were assessed in all operative survivors without PND. Statistical analysis was performed with SASS 10.0 statistical software (SASS Inc).

\section{Results}

\section{Hospital Mortality}

Circulatory arrest and perfusion data are summarized in Table 3.

There were 33 (11.4\%) in-hospital deaths. Hospital mortality for elective surgery was $5.8 \%$, and that for urgent surgery was $17.8 \%(P=.001)$. Causes of death were multiorgan failure $(\mathrm{n}=14)$, PND $(\mathrm{n}=5)$, distal aneurysm rupture $(n=4)$, pneumonia $(n=4)$, hemorrhage $(n=2)$, mediastinitis $(\mathrm{n}=2)$, low cardiac output $(\mathrm{n}=1)$, and bowel ischemia $(\mathrm{n}=1)$.

Univariate analysis revealed that acute type A dissection $(P=.001)$, age greater than 70 years $(P=.018)$, history of cerebral infarction-transient ischemic attack (TIA; $P=$ $.041)$, and Bentall procedure $(P=.012)$ were significant predictors of mortality. A stepwise logistic regression analysis showed that acute type A dissection $(P=.001$; odds ratio $[\mathrm{OR}], 4.3 ; 95 \%$ confidence interval [CI], 1.90-9.67) and age greater than 70 years $(P=.019$; OR, 2.5 ; $95 \% \mathrm{CI}$, 1.57-5.23) were independent predictors of hospital mortality.

\section{Hospital Morbidity}

PND occurred in $27(9.3 \%)$ patients. Univariate analysis revealed acute type A dissection $(P=.001)$ and history of cerebral infarction-TIA $(P=.018)$ to be predictors of stroke. These findings were confirmed by means of stepwise logistic regression (acute type A dissection: $P=.001$; OR, 6.7; 95\% CI, 2.44-18.41; history of cerebral infarction-TIA: $P=.038 ;$ OR, 3.4; 95\% CI, 1.07-11.42). 
TABLE 3. CPB data

\begin{tabular}{|c|c|c|c|c|}
\hline & $\begin{array}{c}\text { Total group, } \\
\text { n (\%) }\end{array}$ & $\begin{array}{c}\text { DHCA, } \\
\text { n (\%) }\end{array}$ & $\begin{array}{l}\text { ASCP, } \\
\text { n (\%) }\end{array}$ & $P$ value \\
\hline CPB time (min) & $198 \pm 74$ & $197 \pm 54$ & $198 \pm 60$ & .982 \\
\hline Myocardial ischemic time (min) & $119 \pm 46$ & $105 \pm 41$ & $129 \pm 48$ & .001 \\
\hline Total cerebral protection time (min) & $35 \pm 21$ & $29 \pm 9$ & $42 \pm 20$ & .001 \\
\hline Nasopharyngeal temperature $\left({ }^{\circ} \mathrm{C}\right)$ & & $16.1 \pm 2.8$ & $23.2 \pm 2.6$ & .001 \\
\hline
\end{tabular}

TND occurred in $21(8.0 \%)$ of the 262 patients who survived surgical intervention without PND. Univariate analysis indicated that acute type A dissection $(P=.002)$ and ejection fraction of less than $50 \%(P=.048)$ were significant predictors of TND. Concomitant procedures $(P=.066)$ and history of cerebral infarction-TIA $(P=$ $.075)$ were of borderline significance. Stepwise logistic regression showed acute type A dissection $(P=.001$; OR, $5.1 ; 95 \%$ CI, 1.87-14.19) to be an independent predictor of TND.

Hospital morbidity included pulmonary complications requiring mechanical ventilatory support for more than 5 days in $36(12.5 \%)$ patients, renal failure requiring temporary hemodialysis in $5(1.7 \%)$ patients, and postoperative myocardial infarction (serum creatine phosphokinase level of $>300 \mathrm{IU} / \mathrm{L}$ with a creatine phosphokinase-MB fraction of $>3 \%)$ in $18(6.2 \%)$ patients. Mean drain blood production was $1524 \pm 1090 \mathrm{~mL}$ (range, 180-7200 mL). Thirtyfive $(12.1 \%)$ patients underwent a repeat thoracotomy for bleeding. Patients received an average of $5.3 \pm 4.2$ units of packed red cells (range, 0-25 units). The average blood product consumption, defined as fresh frozen plasma and platelet consumption, was $5.7 \pm 3.9$ units per patient (range, $0-21$ units). Univariate analysis revealed redo operations $(P=.026)$ and $\mathrm{CPB}$ time of greater than 240 minutes $(P=$ $.012)$ to be risk factors for a greater consumption of packed red cells and blood products.

\section{DHCA Versus ASCP}

The mean CPB times were similar in the DHCA and ASCP groups (DHCA, $198 \pm 54$ minutes; ASCP, $198 \pm 60$ minutes; $P=.982$ ) as a result of prolonged myocardial ischemic protection (DHCA, $105 \pm 41$ minutes; ASCP, $129 \pm 48$ minutes; $P=.001$ ) and total cerebral protection (DHCA, $29 \pm 9$ minutes; ASCP, $42 \pm 20$ minutes; $P=$ .001) times in the ASCP group (Table 3). In fact, more extended aortic tissue replacement and a larger number of aortic root repairs were performed in the ASCP group (Table 2).

Hospital mortality and morbidity of the 2 groups are compared in Table 4.

Hospital mortality was $13.3 \%$ (17/128) in the DHCA group and $9.9 \%(16 / 161)$ in the ASCP group $(P=.375)$. PNDs were more common in the DHCA group (16 [12.5\%]) than in the ASCP group (11 [7.6\%]), although statistical significance was not reached $(P=.075)$. TND occurred in $7.1 \%$ of the DHCA group and $8.7 \%$ of the ASCP group $(P=.530)$. Univariate analysis (Table 5) revealed that a circulatory arrest time of greater than 25 minutes was associated with an increased risk of TND in the DHCA group $(P=.021)$, whereas ASCP duration had no effect on neurologic outcome. ${ }^{1}$ Renal dysfunction (postoperative creatinine level of $>250 \mu \mathrm{mol} / \mathrm{L}$; DHCA, 10 [7.8\%]; ASCP, 6 [3.7\%]; $P=.030$ ) and prolonged intubation time (DHCA, $3.8 \pm 6.3$ days; ASCP, $2.2 \pm 2.5$ days; $P=.005$ ) were more common in the DHCA group. No differences were observed between the 2 groups in terms of drain blood production $(P=.809)$ or packed red cells $(P=.529)$ and blood products consumption $(P=.347)$.

\section{Discussion}

Despite the fact that the results of the surgical intervention of the thoracic aorta have gradually improved, hospital mortality and neurologic and systemic complications still remain considerable. In our series hospital mortality was $11.4 \%$ (5.8\% and $17.8 \%$ in elective and urgent procedures, respectively).

Acute type A aortic dissection and advanced age were independent predictors of hospital mortality, confirming previous reports. ${ }^{1,3,4}$ PND and TND rates were $9.3 \%$ and $8 \%$, respectively. In accordance with other clinical reports, ${ }^{3,4}$ the presence of acute type A aortic dissection and a history of cerebral infarction-TIA predicted the occurrence of postoperative adverse neurologic outcome.

Washiyama and colleagues 5 have demonstrated that a canine brain having a previous cerebral infarction is more susceptible to ischemia during aortic arch operation by using ASCP as a consequence of an accelerated anaerobic metabolism and an increased extracellular glutamate release in the brain from the previous infarction.

Kazui and colleagues ${ }^{6}$ recently reported a postoperative PND rate of $3.3 \%$ in a group of 220 patients undergoing aortic arch replacement with aortic branched grafts and ASCP. The presence of a previous cerebral infarction was an independent determinant of PND, with a relative risk of 21.8 on multivariate analysis.

Similarly, a history of cerebrovascular disease has been 
TABLE 4. DHCA versus ASCP

\begin{tabular}{|c|c|c|c|c|}
\hline & $\begin{array}{c}\text { Total group, } \\
\text { n (\%) }\end{array}$ & DHCA, n (\%) & ASCP, n (\%) & $P$ value \\
\hline Hospital mortality & $33(11.4)$ & $17(13.3)$ & $16(9.9)$ & .375 \\
\hline PND & $27(9.3)$ & $16(12.5)$ & $11(7.6)$ & .075 \\
\hline TND & $21(8.0)$ & $8(7.1)$ & $13(8.7)$ & .530 \\
\hline Intubation time (d) & $2.9 \pm 4.6$ & $3.8 \pm 6.3$ & $2.2 \pm 2.5$ & .005 \\
\hline Postoperative creatinine $>250 \mu \mathrm{mol} / \mathrm{L}$ & $16(5.5)$ & $10(7.8)$ & $6(3.7)$ & .030 \\
\hline Postoperative dialysis & $5(1.7)$ & $1(0.8)$ & $4(2.5)$ & .270 \\
\hline Postoperative MI & $18(6.2)$ & $7(5.5)$ & $11(6.8)$ & .634 \\
\hline Rethoracotomy for bleeding & $35(12.1)$ & $18(14.1)$ & $17(10.6)$ & .365 \\
\hline Drain blood production & $1524 \pm 1090$ & $1542 \pm 1242$ & $1509 \pm 952$ & .809 \\
\hline Packed red cells & $5.3 \pm 4.2$ & $5.4 \pm 5.0$ & $5.1 \pm 3.5$ & .529 \\
\hline Blood products consumption & $5.7 \pm 3.9$ & $5.4 \pm 4.0$ & $5.9 \pm 3.7$ & .347 \\
\hline
\end{tabular}

MI, Myocardial infarction.

shown to be an independent predictor of postoperative stroke in aortic arch replacement with DHCA alone..$^{3,4}$

DHCA with or without retrograde cerebral perfusion and ASCP are currently being used as methods of brain protection.

Technical simplicity and avoidance of aorta and arch vessel manipulation, as well as a bloodless operative field, make DHCA an attractive method of brain protection, especially during ascending aorta-hemiarch replacement, when a short period of circulatory arrest is anticipated. However, hypothermia-associated coagulopathy ${ }^{7}$ and pulmonary, renal, and microembolic complications ${ }^{8}$ are important disadvantages cited in the literature.

ASCP provides several advantages: the circulatory arrest time can safely be extended up to 90 minutes, ${ }^{1}$ allowing more complex aortic repair to be performed, and moderate (nasopharyngeal temperature $25^{\circ} \mathrm{C}$ ) instead of profound hypothermia can be used with reduced coagulative and systemic complications. Criticism against ASCP includes technical complexity, reduced surgical visibility, and manipulation of the aortic arch and arch vessels, especially in cases of acute dissection or severely atherosclerotic aortic arch aneurysm.

In the current study we compared DHCA and ASCP in terms of hospital mortality and neurologic and systemic morbidity in a group of patients undergoing ascending aorta-hemiarch replacement.

In our series the patients in the ASCP group had a more extended aortic tissue replacement and a larger number of aortic root repairs. Nevertheless, hospital mortality and neurologic outcome were comparable in the 2 groups; reduced intubation time and better renal function recovery were noted in the ASCP group.

TND seems to be a manifestation of subtle but diffuse brain injury associated with long-lasting cognitive impairment undetectable by means of conventional imaging techniques and directly correlated to inadequate brain protection. ${ }^{9}$
TABLE 5. TND patient distribution by DHCA time

\begin{tabular}{cccc}
\hline & DHCA time $<25$ min & DHCA time $>\mathbf{2 5}$ min & $P$ value \\
\hline TND & & & \\
Yes & $1(1.9 \%)$ & $7(11.9 \%)$ & .021 \\
No & $52(98.1 \%)$ & $52(88.1 \%)$ & \\
\hline
\end{tabular}

In our series a circulatory arrest time of greater than 25 minutes was associated with an increased risk of TND in the DHCA group.

Reich and colleagues ${ }^{10}$ have demonstrated that a DHCA time of 25 minutes or greater is associated with memory and fine motor deficits, as well as with prolonged hospital stays. McCullough and colleagues ${ }^{11}$ have recently demonstrated that the cerebral metabolic rate is still $17 \%$ of the baseline at $15^{\circ} \mathrm{C}$ and that the safe duration of circulatory arrest at $15^{\circ} \mathrm{C}$ is only 29 minutes. These findings probably indicate that circulatory arrest times of 45 to 60 minutes were too optimistically indicated as safe. ${ }^{4}$

Surprisingly, no significant differences in terms of rethoracotomy for bleeding, drain blood loss, and blood products consumption was observed between the 2 groups. This was probably because of similar mean CPB times in the 2 groups or damage of the blood components occurring during perfusion through the small ASCP cannulas.

In conclusion, even though this study carries the risks inherent to the use of retrospective data, some important conclusions can be reached: (1) the use of DHCA and ASCP resulted in acceptable results in terms of hospital mortality and neurologic outcome during ascending aorta-hemiarch replacement; (2) only preoperative patient characteristics, such as acute type A aortic dissection, age greater than 70 years, and history of cerebral infarction-TIA, affected hospital mortality and neurologic outcome; (3) in the DHCA group a circulatory arrest time of more than 25 minutes was associated with an increased risk of TND; and (4) reduced 
postoperative intubation time and better renal function recovery were observed in the ASCP group.

\section{References}

1. Di Eusanio M, Schepens MA, Morshuis WJ, Di Bartolomeo R, Pierangeli A, Dossche KM. Antegrade selective cerebral perfusion during operations on the thoracic aorta: factors influencing survival and neurologic outcome in 413 patients. J Thorac Cardiovasc Surg. 2002;124:1080-6.

2. Dossche KM, Morshuis WJ, Schepens MA, Waanders FG. Bilateral antegrade selective cerebral perfusion during surgery on the proximal thoracic aorta. Eur J Cardiothorac Surg. 2000;17:462-7.

3. Ergin MA, Galla JD, Lansman s, Quintana C, Bodian C, Griepp RB. Hypothermic circulatory arrest in operations on the thoracic aorta. Determinants of operative mortality and neurologic outcome. J Thorac Cardiovasc Surg. 1994;107:788-97.

4. Svensson LG, Crawford ES, Hess KR, Coselli JS, Raskin S, Shenaq SA, et al. Deep hypothermia with circulatory arrest: determinants of stroke and early mortality in 656 patients. J Thorac Cardiovasc Surg. 1993;106:19-28.

5. Washiyama N, Kazui T, Takinami M, Yamashita C, Fujita S, Terada $\mathrm{H}$, et al. Experimental study on the effect of antegrade cerebral perfusion on brains with old cerebral infarction. J Thorac Cardiovasc Surg. 2001;122:734-40.

6. Kazui T, Washiyama N, Muhammad BA, Terada H, Yamashita K, Takinami M, et al. Total arch replacement using aortic arch branched grafts with the aid of antegrade selective cerebral perfusion. Ann Thorac Surg. 2000;70:3-8.

7. Livesay JJ, Cooley DA, Reul GJ, Walker WE, Fraizer OH, Duncan $\mathrm{JM}$, et al. Resection of aortic arch aneurysms: a comparison of hypothermic techniques in 60 patients. Ann Thorac Cardiovasc Surg. 1983;36:19-28.

8. Cooper WA, Duarte IG, Thourani VH, Nakamura M, Wang NP, Brown MB, et al. Hypothermic circulatory arrest causes multisystem vascular endothelial dysfunction and apoptosis. Ann Thorac Cardiovasc Surg. 2000;69:696-703.

9. Ergin MA, Uysal S, Reich DL, Apaydin A, Lansman SL, McCullough JN, et al. Temporary neurological dysfunction after deep hypothermic circulatory arrest: a clinical marker of long-term functional deficit. Ann Thorac Surg. 1999;67:1887-90.

10. Reich DL, Uysal S, Sliwinski M, Ergin MA, Kahn RA, Konstadt SN, et al. Neuropsychologic outcome after deep hypothermic circulatory arrest in adults. J Thorac Cardiovasc Surg. 1999;117:156-63.

11. McCullough JN, Zhang N, Reich DL, Juvonen TS, Klein JJ, Spielvogel $\mathrm{D}$, et al. Cerebral metabolic suppression during hypothermic circulatory arrest in humans. Ann Thorac Surg. 1999;67:1895-9.

\section{Appendix}

Age $>70 y$

Sex

Acute dissection

Status (elective-urgent)

Ejection fraction

Hypertension

Diabetes

Preoperative renal creatinine level $(\mu \mathrm{mol} / \mathrm{L})$

Preoperative dialysis

History of central neurologic events

Previous cardiovascular surgery by means of median sternotomy

Extent of replacement (ascending aorta-hemiarch)

Associated procedures (all combined)

Concomitant aortic valve replacement

Concomitant aortic valve-sparing procedures

Concomitant aortic valve suspension

Concomitant Bentall procedure

Concomitant homograft

Concomitant coronary artery bypass grafting

CPB time

CPB time $>240 \mathrm{~min}$

Myocardial ischemic time

Myocardial ischemic time $>120 \mathrm{~min}$

Selective cerebral perfusion time

Exitus

Postoperative intubation time (d)

Postoperative myocardial infarction

Postoperative creatinine level $>250 \mu \mathrm{mol} / \mathrm{L}$

Postoperative hemodialysis

Blood drain production $(\mathrm{mL})$

Bleeding requiring rethoracotomy

Packed red cells consumption (in units)

Blood products consumption (in units)

Permanent neurologic dysfunction

Transient neurologic dysfunction 